\title{
PHYSIOLOGICAL AND PATHOLOGICAL EFFECTS OF SEVERE EXERTION (THE MARATHON RACE) ON THE CIRCULATORY AND RENAL SYSTEMS *
}

\author{
JOSEPH H. BARACH, M.D. \\ PITTSBURG, PA.
}

\section{INTRODUCTION}

One of the decisive battles of the world was fought in year $490 \mathrm{~B}$. C. Miltiades, a Greek general, commanding an army of but 11,000 men, defeated the Persians, numbering over 100,000. The conflict took place on the Marathon plain. After the battle a soldier was dispatched to carry the news of victory to Athens, a distance of 40 kilometers (24.85 miles). As he reached his destination, having run without stopping, and as he emitted the words, "Victory is ours," he fell dead.

In 1896 the Grecian government established the course covered by this unknown soldier as an official event of the Olympic games. America was not especially interested in this until an American youth, in 1908, won the race. Since then it has become popular on this continent; it has, in fact, become almost a craze with the American boys to train for and compete in these races.

It can easily be seen what a fertile soil for study of the circulatory system such youths might furnish, and this study has, along certain lines, been made with fruitful results.

\section{HISTORICAL}

In 1899 Drs. Williams and Arnold ${ }^{1}$ studied a series of these cases. From 1900 to 1903 Drs. J. B. Blake and R. C. Larrabee ${ }^{2}$ studied the contestants who ran in the Boston Athletic Association race. Since then a series of these have been studied by Drs. Nathaniel B. Potter and James T. Harrington. ${ }^{3}$ The work reported so far is admirable and full of interesting findings, much of which all investigators in the future will find themselves repeating. The most difficult problem that presents itself to

*Presented by invitation before the American Physiological Society, Dec. 30, 1909, Boston.

1. Williams and Arnold: Effect of Violent and Prolonged Muscular Exercise on the Heart, Philadelphia Med. Jour., 1899, iii, 1233.

2. Blake, J. B., and Larrabee, R. C.: Observations upon Long-Distance Runners, Boston Med. and Surgical Jour., 1903, cxlviii, 195.

3. Potter, N. B., and Harrington, J. T.: Medical Supervision of Athletics Among Boys at Boarding Sehools, Jour. Am. Med. Assn., 1909, liii, 1957. 
the investigator along this line is the handling of these youths and men. In our work this was made comparatively easy for us by the Pittsburg Athletic Association. They made it imperative that the contestants present themselves for examinations at the specified times, and with that they liberally furnished us everything necessary and convenient to make these studies successful in every possible way. For all this we wish to express our sincerest appreciation, and we feel that the results that they have made possible have warranted their liberality.

The work here considered is but one phase of the studies carried out by Dr. Watson L. Savage, Dr. John W. Boyce and myself. My part of the work is limited to the circulatory and renal systems, and I present the observations here in the order in which they were made.

The 55 contestants in this race were youths and men from the ordinary walks of life, and most of them were new recruits to this form of exertion.

PULSE-RATE DURING TRAINING

At some time during the week before the run we had the contestants count their pulse in the morning before getting out of bed and in the evening before retiring. They all ran their training distance on that day, which varied from 2 to 18 miles, the average being $\%$.

Table 1 shows the morning pulse to have been below 71 in 13 out of 16 cases, and the evening pulse was below 71 in 10 out of 16 cases. Taken as a whole, the pulse-rate is a little slower than what is considered normal for the average individual.

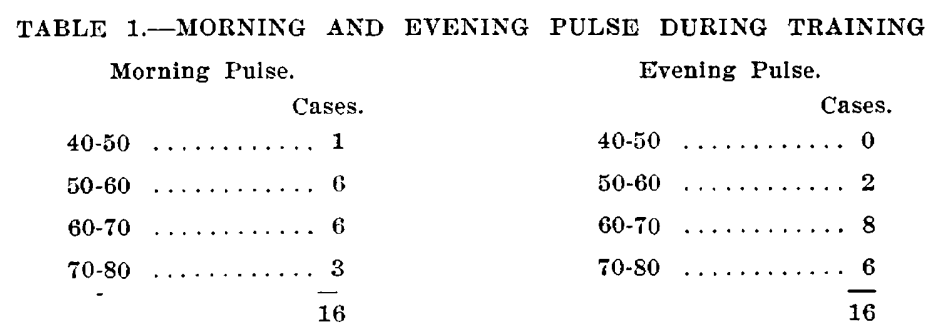

RELATION OF MORNING AND EVENING PULSE

I noticed that in about half of the number there was a marked difference between the morning and evening pulse-rate. In Table 2 these cases are separated in two groups. A further study brought out the interesting fact that those subjects who showed the greater diurnal variation had higher blood-pressures. And there was but one subject that showed high blood-pressure who did not have this marked diurnal variation. 
The subjects in the second group are further advanced in life than those of the first group and a higher blood-pressure is to expected; nevertheless, as will be seen later, these readings are higher than they should be, all things considered.

TABIE 2.-MORNING AND EVENING PULSE DURING TRAINING

\begin{tabular}{cccccccc}
\multicolumn{3}{c}{ Normal Variation } & \multicolumn{5}{c}{ Hypernormal Variation } \\
Age. & A.M. & P.M. & B.-P. & Age. & A.M. & P.M. & B.-P. \\
18 & $\mathbf{7 2}$ & 68 & 110 & 20 & 52 & 53 & $140^{*}$ \\
19 & 58 & 58 & 118 & 21 & 60 & 74 & 135 \\
19 & 54 & 64 & 120 & 25 & 50 & 70 & 150 \\
22 & 60 & 65 & 125 & 29 & 60 & 74 & 162 \\
22 & 70 & 74 & 125 & 31 & 48 & 67 & 138 \\
29 & 64 & 66 & 115 & 36 & 55 & 65 & 132 \\
29 & 60 & 62 & 122 & 36 & 70 & 78 & 140 \\
29 & 65 & 71 & 120 & 52 & 56 & 68 & 134 \\
* Exceptional case. & & & & & &
\end{tabular}

PULSE-RATE BEFORE THE RACE

The pulse-rate was taken in the horizontal position in all cases before the race. Half of them on the preceding evening and the others in the forenoon within three hours before the race. So far as could be estimated, the psychic influence of our investigations on these contestants at this time was not a considerable factor, as we made an effort to put them at ease so as to eliminate, if possible, such influence on the pulse-rate ind blood-pressure readings.

Table 3 shows that, while the pulse varied from 50 to 110 , in most cases it was normal.

TABLE 3.-PULSE-RATE JIEFORE RACE

\begin{tabular}{|c|c|c|c|}
\hline No. Cases. & I'ulse-Rate. & No. Cases. & Pulse-Rate. \\
\hline $2 \ldots$ & . $50-55$ & 10 & $80-85 \div$ \\
\hline $0 \ldots$ & $5 \overline{5}-60^{*}$ & 1 & . $\quad 85-90$ \\
\hline $7 \ldots$ & $60-65 *$ & 2 & $90-95$ \\
\hline $11 \ldots$ & . $65-70^{*}$ & $2 \ldots$ & . $\quad 95-100$ \\
\hline $9 \ldots$ & . $\tau 0-75^{*}$ & 1 & $100-105$ \\
\hline $8 \ldots$ & . . $75-80 \dagger$ & 2 & $10 \overline{5}-110$ \\
\hline
\end{tabular}

Total number of cases, 55 .

* Pulse-rate $5 \overline{5}$ to 75,27 cases. $\dagger$ Pulse-rate 75 to 85,18 cases. 
BLOOD-PRESSURE STUDIES

These records were made with the Erlanger and the Stanton sphygmomanometers. They were both fitted with the same width rubber cuff (10 cm.) and had been previously tested and compared. All the work referred to in this paper was performed with the instruments used in these observations.

Before the race we obtained complete records made with the Erlanger instrument in 24 cases and with the Stanton in 21. No attempt was made at reading the diastolic pressure with the Stanton instrument.

NORMAL BLOOD-PRESSURE

As a basis for comparison in this series a curve was constructed based on 90 blood-pressure observations in normal males at the succeeding years. This is shown in Chart 1 and the succeeding charts of averages. $O t$ the individuals of 60 and over, while it may be said that they should not be considered normal on account of the changes that are invariably present at that age, yet I can affirm that they were distinctly free from marked evidences of disease.

It will be noted that with the advance of years the curve gradually tends upward. This seems in accordance with the fact that the heart enlarges as the age of the individual progresses.

With this line as a normal level of the maximum blood-pressure, in all of my observations in the past, I have found that a variation of more than $25 \mathrm{~mm}$. above or below is usually associated with evidence of disease.

MAXIMCA BLOOD-PRESSURE BEFORE RACE

These determinations were made with the Erlanger instrument cighteen hours before the race in 24 cases, and with the Stanton two hours before the race in the other 29 of the series. The average maximum blood-pressure of the entire series of 53 cases was $126.5 \mathrm{~mm}$.

The average maximum of these cases, arranged according to the age, is shown in Table 4, which shows the constancy and regularity with which the blood-pressure rises as age advances.

TABLE 4.-AVERAGE MAXIMUM BLOOD-PRESSURE BEFORE RACE IN 45 CASES

$\begin{array}{ccc}\text { No. Cases. } & \text { Age. } & \text { Average Maximum B.-F. } \\ 12 & 18-20 & 122.75 \\ 20 & 20-25 & 125.05 \\ 11 & 25-30 & 129.00 \\ 2 & 30.35 & 136.00\end{array}$


The average maximum, minimum and pulse-pressures of these contestants, first in the horizontal and then in the erect position of the body, is to be seen in Table 5. These cases are arranged in the order in which the contestants finished in the race. As is well known, the change of the body posture causes certain alterations in the relation of the pulse and blood-pressures. These are noted in the last column of the table as plus, minus and equal. The conclusions from these will be commented on later.

TABLE 5.-BLOOD-PRESSURES BEFORE THE RACE IN HORIZONTAL AND ERECT POSTURES

\begin{tabular}{|c|c|c|c|c|c|c|c|c|c|c|c|c|c|}
\hline \multirow{2}{*}{ No. } & \multirow[b]{2}{*}{ Age. } & \multicolumn{4}{|c|}{-Horizontal- } & 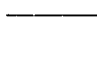 & -Erec & B.-P. & - - & \multicolumn{3}{|c|}{ Result. } & \multirow[b]{2}{*}{ P..P. } \\
\hline & & Pulse. & s. & D. & P.-I'. & Pulse. & s. & D. & P.-F. & P. & s. & D. & \\
\hline 4 & 18 & 72 & 110 & 90 & 20 & 72 & 115 & 80 & $3 \overline{5}$ & $=$ & + & - & + \\
\hline$\tilde{\mathbf{j}}$ & 28 & 105 & 132 & 98 & 34 & 97 & 128 & 95 & 33 & - & - & - & - \\
\hline$\tau$ & 36 & 63 & 132 & 100 & 32 & 76 & 132 & 100 & 32 & + & $=$ & $=$ & $=$ \\
\hline 11 & 19 & 78 & 120 & 85 & 35 & 90 & 120 & 80 & 40 & + & $=$ & $\rightarrow$ & + \\
\hline 12 & 21 & 76 & 145 & 100 & 45 & 80 & 145 & 100 & 45 & + & $=-$ & $=$ & $=$ \\
\hline 13 & 22 & 74 & 125 & 100 & 25 & 76 & 122 & 100 & 22 & + & - & $=$ & - \\
\hline 15 & 19 & 84 & 110 & 90 & 20 & 84 & 118 & 85 & 33 & $=$ & + & - & + \\
\hline 17 & 23 & 106 & 135 & 90 & 45 & 106 & $13 \bar{\Xi}$ & 100 & 35 & $=$ & $=$ & + & - \\
\hline 19 & 27 & 66 & 122 & 90 & 32 & 76 & 118 & 90 & 28 & + & $\longrightarrow$ & $=$ & - \\
\hline 22 & 21 & 80 & 130 & 100 & 30 & 83 & 132 & 110 & 22 & + & + & + & - \\
\hline \pm & 27 & 67 & 120 & 95 & 25 & 72 & 130 & 100 & 30 & + & + & + & + \\
\hline 27 & 19 & 54 & 118 & 92 & 26 & 74 & 112 & 92 & 20 & + & 一 & $=$ & - \\
\hline 30 & 25 & 65 & 110 & 90 & 20 & 70 & 112 & 98 & 14 & + & + & + & - \\
\hline 0 & 52 & 82 & 134 & 100 & 34 & 78 & 138 & 100 & 38 & - & + & $=$ & + \\
\hline 38 & 21 & 69 & 124 & 50 & 29 & 76 & 120 & 100 & 20 & + & 一 & + & - \\
\hline 39 & 19 & 87 & 155 & 130 & 25 & 84 & 142 & 118 & 24 & - & - & - & - \\
\hline 40 & 23 & 66 & 133 & 110 & 23 & 66 & 135 & 100 & 35 & $=$ & + & - & + \\
\hline 41 & 0 & 64 & 130 & 09) & 30 & 64 & 132 & 90 & (1) & $=$ & + & - & + \\
\hline 43 & 20 & 75 & 120 & 88 & 32 & 76 & 100 & 80 & 20 & + & - & - & - \\
\hline 47 & 29 & 83 & 162 & 112 & $\overline{50}$ & 85 & 150 & 105 & 45 & + & - & - & - \\
\hline 70 & 27 & 62 & 130 & 100 & 30 & 72 & 120 & 100 & 20 & + & - & $=$ & - \\
\hline 49 & 27 & 72 & 130 & 95 & 35 & 70 & 132 & 100 & 32 & - & + & + & - \\
\hline 50 & 21 & 70 & 105 & 85 & 20 & 70 & 110 & 85 & 25 & $=$ & + & $=$ & + \\
\hline 51 & 18 & 76 & 118 & 95 & 23 & 83 & 110 & 95 & 15 & + & - & $=$ & - \\
\hline 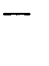 & - & $\cdots$ & 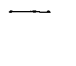 & - & 一 & - & -.- & $-\cdots$ & 一 & $\overline{+14}$ & $\overline{+10}$ & $\overline{+8}$ & $\overline{+8}$ \\
\hline & age & 74.8 & 27 & 96.7 & 0. & 78.3 & 124.9 & 95.9 & 9.3 & $\begin{array}{l}-4 \\
=6\end{array}$ & $\begin{array}{l}-11 \\
=3\end{array}$ & $\begin{array}{l}-9 \\
=9\end{array}$ & $\begin{array}{l}-14 \\
-2\end{array}$ \\
\hline
\end{tabular}


TABLE 6.-MAXIMUM, MINIMUM AND PULSE-PRESSURE BEFORE RACE ACCORDING TO AGE

HORIZONTAL

\begin{tabular}{|c|c|c|c|c|c|c|c|c|c|c|c|}
\hline -Age & 18 to & $20-$ & -Age & 20 to & $25-$ & -Age & 25 to & $30-$ & $-A g$ & e 35 to & $40-$ \\
\hline Max. & Min. & P.-P. & Max. & Min. & P.-P. & Max. & Min. & P.-P. & Max. & Min. & P.-P. \\
\hline 110 & 90 & 20 & 145 & 100 & 45 & 132 & 98 & 34 & 132 & 100 & 32 \\
\hline 120 & 85 & 35 & 125 & 100 & 25 & 122 & 90 & 32 & $\ldots$ & $\cdots$ & . \\
\hline 110 & 90 & 20 & 135 & 90 & $4 \overline{5}$ & 120 & 95 & 25 & $\ldots$ & $\ldots$ & . \\
\hline 118 & 92 & 26 & 130 & 100 & 30 & 110 & 90 & 20 & $\ldots$ & $\cdot$ & .. \\
\hline 155 & 130 & 25 & 124 & 95 & 29 & 162 & 112 & 50 & $\ldots$ & .. & . \\
\hline 118 & 95 & 23 & 133 & 110 & 23 & 130 & 100 & 30 & $\ldots$ & $\ldots$ & . \\
\hline$\ldots$ & . & $\ldots$ & 120 & 88 & 32 & 130 & 95 & 35 & & $\triangle \mathrm{AL}_{2} \quad 22$ & \\
\hline$\ldots$ & $\ldots$ & . & 105 & 85 & 20 & $\ldots$ & . & $\ldots$ & 134 & 100 & 34 \\
\hline Average: & & & & & & & & & & & \\
\hline 121.8 & 97. & 24.8 & 123.3 & 96. & 31. & 129. & 08. & 32. & & & \\
\hline & & & & & ERF & & & & & & \\
\hline 115 & 80 & 35 & 145 & 100 & 45 & 128 & 95 & 33 & 132 & 100 & 32 \\
\hline 120 & 80 & 40 & 122 & 100 & 22 & 118 & 90 & 28 & $\ldots$ & $\ldots$ & . \\
\hline 118 & $8 \tilde{5}$ & 33 & 135 & 100 & 35 & 130 & 100 & 30 & $\ldots$ & $\ldots$ & $\cdots$ \\
\hline 112 & 32 & 20 & 132 & 100 & 22 & 112 & 98 & 14 & $\ldots$ & $\cdots$ & $\cdots$ \\
\hline$\ldots$ & $\ldots$ & $\cdots$ & 120 & 100 & 20 & 150 & 105 & 45 & $\ldots$ & $\cdots$ & . \\
\hline 142 & 118 & 24 & $\ldots$ & $\cdots$ & . & $\ldots$ & $\ldots$ & $\ldots$ & $\ldots$ & $\cdots$ & . \\
\hline$\ldots$ & $\ldots$ & . & $13 \overline{5}$ & 100 & 35 & 120 & 100 & 20 & $\ldots$ & $\cdots$ & $\cdots$ \\
\hline 110 & 95 & 15 & $\ldots$ & $\ldots$ & . & $\ldots$ & $\ldots$ & $\ldots$ & $\ldots$ & $\cdots$ & . \\
\hline$\ldots$ & $\ldots$ & . & 100 & 80 & 20 & 132 & 100 & 32 & & $\triangle \mathrm{AGE} \check{52}$ & \\
\hline$\ldots$ & $\ldots$ & . & 110 & 85 & 25 & $\ldots$ & $\ldots$ & $\ldots$ & 138 & 100 & 38 \\
\hline verage : & & & & & & & & & & & \\
\hline 119.5 & 91.6 & 27.8 & 124.8 & 95.6 & 28. & 127. & 98.2 & 28.8 & & & \\
\hline
\end{tabular}

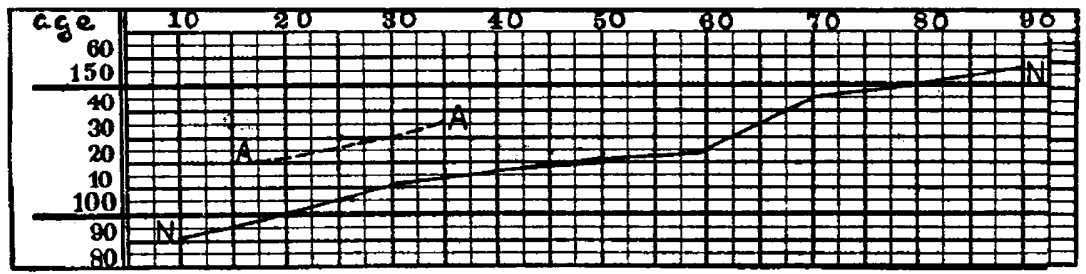

Fig. 1.- Average maximum blood-pressure (before the race) of contestants (line $A-A$ ) compared with average maximum blood-pressure in 00 normal men (line $\mathrm{N} N$ ).

On the maximum blood-pressures in all the subjects at their respective ages $I$ have constructed the chart shown in Figure 1 , and it is to be noted that this curve is at about the upper limit of the normal bloodpressure zone. 
RELATION OF BODY WEIGHT TO BLOOD-PRESSURE

Table $r$ shows that half of the orerweighted subjects and a little over a third of the underweighted subjects had higher than average bloodpressure. Between the degree of overweight and the height of the bloodpressure there was no relation whatever.

TABLE 7.-RELATION OF BODY WEIGHT TO BLOOD-PRESSURE

53 Cases

\begin{tabular}{lcc} 
& \multicolumn{4}{c}{ Cases. } & Hypertension. \\
Underweight $\ldots \ldots \ldots \ldots \ldots \ldots \ldots$ & 34 & $\mathbf{3 0}$ \\
Overweight $\ldots \ldots \ldots \ldots \ldots \ldots \ldots$ & 16 & 8 \\
Normal $\ldots \ldots \ldots \ldots \ldots \ldots \ldots \ldots$ & 3 & 0
\end{tabular}

RELATION OF OCCUPATION TO BLOOD-PRESSURE

The occupations were subdivided according to the amount of physical strain. Only those were classified with the hypertension cases whose pressures were distinctly above the average for the age of the subjects.

TABLE 8.-RELATION OF OCCLIATION TO RLOOD-PIESSURE

B.-P, Average.

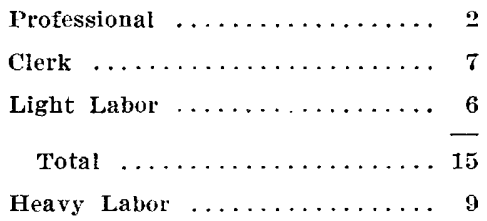

B.-P. Above Average.

1

1

2

4

13

RELATION OF PREVIOUS MARATHON RLNS TO BLOOD-PRESSURE

Some of the contestants were experienced long-distance runners, but most of them had partaken in long-distance races not more than one year; so that the extra strain thrown on the circulatory system was rather sudden and in some instances it was persistent during the entire year or less.

Table 9 shows the number of races run and the time of long-distance running. The runners showing high blood-pressure are in those who had trained for and run from three to five races within the first year of their experience. The experienced runners of nine, ten, eleven and twenty years all had average blood-pressures. 
TABLE 9.-PREVIOUS RUNS AND BLOOD-PRESSURE

Years Long Dis. Kun. Marathon Races.

20

11

10

\section{9}

2

\section{1}

\section{1}

1

1

1

1

1

1

1

1

\section{8}

3

3

4

5

5

5

4

4

3

3

3

3

3

2
Blood-Pressure.

Average

Average.

Average

Average

Average

High

High

High

Average

High

High

Average

Average

Average

Average

\section{HEART CASES}

Auscultation was carried out in every one of the 55 contestants, within twenty-four hours before the race, with abnormal findings in seven (ases, as shown in Table 10.

TARII: 10.-HEART CASES

\section{Cases.}

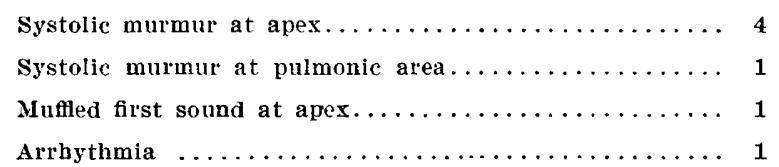

On inspection, a considerable number showed very prominent apex beat, and in nearly all cases the impulse was plainly visible. Percussion was not carried out, as the presence of hypertrophy was to be determined by a more accurate method.

\section{BLOOD-PRESSURE IN HEART-MURMUR CASES}

In each of the five murmur cases there was a maximum and minimum pressure distinctly above the normal line, and four of them showed a pressure very much higher than the arerage height.

Table 11 gives the readings in these cases, and Figure 2 shows their maximum blood-pressure as compared with the other athletes and normal individuals. 
TABLE 11.-HEART-MURMLR CASES

$\begin{array}{ccc}\text { Age. } & \text { Max. Blood-Pressure. } & \text { Min. Blood-Pressure. } \\ 18 & 110 & 90 \\ 19 & 155 & 130 \\ 21 & 140 & 100 \\ 29 & 162 & 112 \\ 36 & 132 & 110\end{array}$

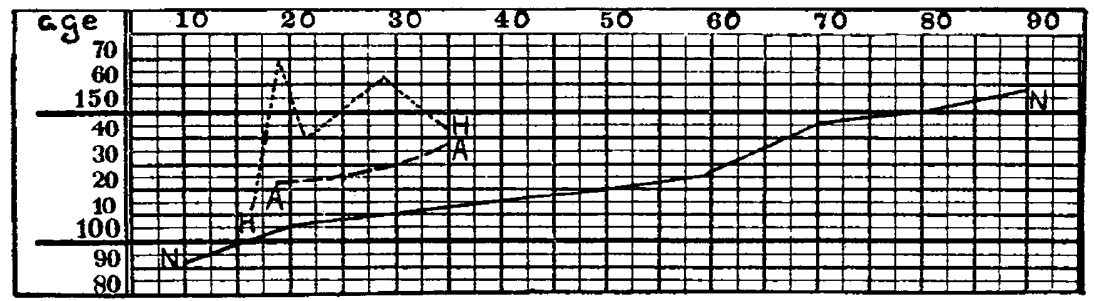

Fig. 2.-Average maximum blood-pressure (line H-H) of five contestants with heart murmurs (before the race) compared with average maximum blood-pressure of other contestants (line $\mathbf{A}-\mathbf{A}$ ) and of normal men (line $\mathrm{N}-\mathrm{N}$ ).

\section{RELATION OF ILEART CASES TO BODY WEIGHT}

Having learned that in these cases there was no history of cardiac involvement from disease, I thought it might be of interest to search for other causative factors. We have studied the age, height and weight of these contestants and classified them as over, under and normal weight. The relation of these heart cases to the body weight is shown in Table 12.

\section{TABLE 12.-BODY WEIGHT IN HEART CASES}

Before Race.

Heart. Weight.*

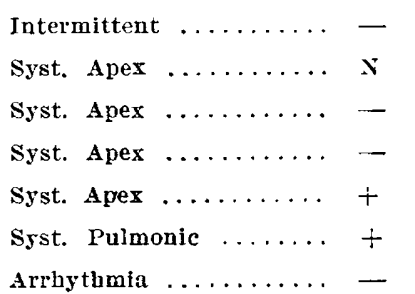

After Race.

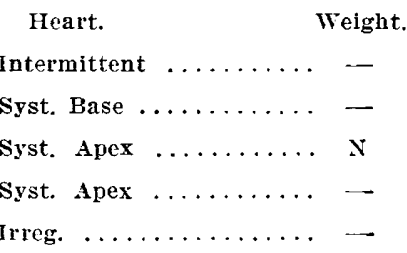

* In this column + means overweight ; - underweight, and $\mathrm{N}$, normal.

The table shows that the murmurs were entirely independent of body overweight, and that the proportion of underweight cases is about the same as in the entire series. 
BLOOD-PRESSURE AFTER THE RACE

The blood-pressure readings were made immediately after the finish in nearly every case. In only a few instances was it delayed four or five minutes after entrance to the medical tent. For comparison, the readings obtained before the race are repeated in the following tables. The average of the maximum pressures before the race was 126.5 (53 cases) and $10 \% .3$ (38 cases) after the race.

Table 13 gives the readings in the individual cases after the race and the average pulse-rate, maximum, minimum and pulse-pressures, in the horizontal and erect postures. The effects resulting from the change of posture are to be noted in the last column.

TABLE 13.-PULSE-RATE AND BLOOD-PRESSURE IN HORIZONTAL AND ERECT POSTURES AFTER THE RACE

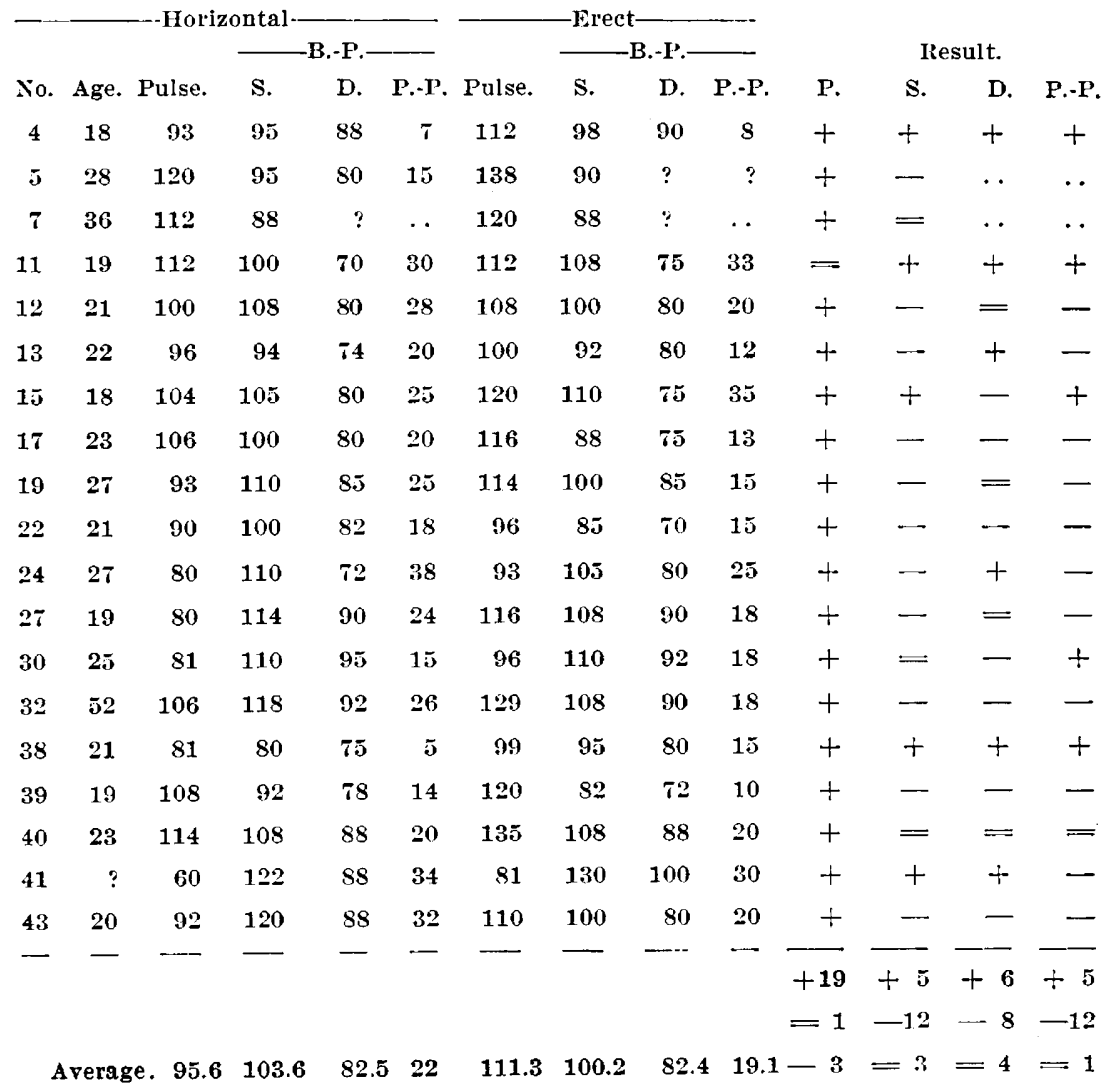


The averages of the readings after the race (Table 13), as compared with the findings previous to the race, are shown in Table 14.

TABLE 14.-PULSE-RATE, MAXIMLM. MINIMUM AND PULSE-PRESSURE, BEFORE AND AFTER THE RACE

\begin{tabular}{|c|c|c|c|c|c|c|c|c|c|}
\hline \multirow[b]{3}{*}{ Refore } & \multirow{2}{*}{ Cases. } & \multicolumn{4}{|c|}{ Lorizontal } & \multicolumn{4}{|c|}{-Erect } \\
\hline & & P'ulse. & Max. & Min. & P.-P. & Pulse. & Max. & Min. & P.-P. \\
\hline & 24 & 74.8 & 127.8 & 96.7 & 30.3 & 78.3 & 124.0 & 95.9 & 29.3 \\
\hline After & 19 & 95.6 & 103.6 & 82.5 & 22.0 & 111.3 & 100.2 & 82.4 & 19.1 \\
\hline
\end{tabular}

Arranged according to age, the individual readings are to be seen in Table 15.

\begin{tabular}{|c|c|c|c|c|c|c|c|c|c|c|c|}
\hline \multirow{3}{*}{ TABLE } & 15. -1 & MAXIM & $\begin{array}{l}\mathrm{UM}, \quad \mathrm{MI} \\
\mathrm{ACCORI}\end{array}$ & $\begin{array}{l}\text { INIMU } \\
\text { DING }\end{array}$ & $\begin{array}{l}\text { M AND } \\
\text { TO AGE } \\
\text { HORIzON }\end{array}$ & $\begin{array}{l}\text { D PUL } \\
\text { E OF } \\
\text { TTAL }\end{array}$ & $\begin{array}{l}\text { CSE-PR } \\
\text { SUBJE }\end{array}$ & $\begin{array}{l}\text { ESSURE } \\
\text { CTS }\end{array}$ & $A F T$ & TER & RACE, \\
\hline & 18 to & $20-$ & -Agre & 20 to & $25-$ & - Age & 25 to & $30-$ & -Age & e 35 to & $40-$ \\
\hline & Min. & P.-P. & Max. & Min. & I.-P. & Max. & Min. & P.-P. & $\operatorname{Max}$. & Min. & P.-P. \\
\hline 95 & 88 & 7 & 108 & 80 & 28 & 95 & 80 & 15 & 88 & $?$ & $?$ \\
\hline 100 & 70 & 30 & 94 & 74 & 20 & 110 & 85 & 25 & $\ldots$ & . & .. \\
\hline 105 & 80 & 25 & 100 & 80 & 20 & 110 & $\pi: 2$ & 38 & $\ldots$ & . & . \\
\hline 114 & 90 & 24 & 100 & 82 & 18 & 110 & 95 & 15 & $\ldots$ & $\cdots$ & .. \\
\hline$\ldots$ & . & $\cdots$ & 80 & 75 & 5 & $\cdots$ & . & . & $\ldots$ & . & . \\
\hline 92 & 78 & 14 & $\ldots$ & . & . & $\ldots$ & $\ldots$ & . & $\ldots$ & . & . \\
\hline$\ldots$ & . & $\ldots$ & 108 & 88 & 20 & $\ldots$ & . & $\ldots$ & & AGE 52 & \\
\hline$\ldots$ & $\ldots$ & $\ldots$ & 120 & 88 & 32 & $\ldots$ & . & $\ldots$ & 118 & 92 & 26 \\
\hline Average: & & & & & & & & & & & \\
\hline 101.2 & 81.2 & 20. & 101.4 & 81. & 20.4 & 106.2 & 83. & 23.2 & & & \\
\hline & & & & & EREC' & & & & & & \\
\hline 98 & 90 & 8 & 100 & 80 & 20 & 90 & $?$ & $?$ & 88 & $?$ & $?$ \\
\hline 108 & 75 & 33 & 92 & 80 & 12 & 100 & 85 & 15 & $\ldots$ & . & . \\
\hline 110 & 75 & 35 & $\ldots$ & $\ldots$ & .. & $\ldots$ & $\ldots$ & $\ldots$ & $\ldots$ & $\ldots$ & . \\
\hline$\ldots$ & .. & $\ldots$ & $8 \overline{0}$ & 70 & 15 & 110 & 92 & 18 & $\ldots$ & $\ldots$ & .. \\
\hline 108 & 90 & 18 & $\ldots$ & . & . & $\ldots$ & . & . & $\cdots$ & . & . \\
\hline$\ldots$ & $\ldots$ & $\ldots$ & 95 & 80 & 15 & $\ldots$ & . & . & $\ldots$ & $\ldots$ & . \\
\hline 82 & 70 & 10 & $\ldots$ & . & . & $\ldots$ & . & . & $\cdots$ & . & . \\
\hline$\ldots$ & . & . & 108 & 88 & 20 & $\ldots$ & . & $\cdots$ & & AGE 52 & \\
\hline$\ldots$ & $\ldots$ & . & 100 & 80 & 20 & $\ldots$ & . & . & 108 & 90 & 18 \\
\hline $\begin{array}{c}\text { Average : } \\
101.2\end{array}$ & 80.4 & 20.8 & $9 \overline{5} .4$ & 79. & 16.4 & 101.1 & 85.6 & 19.3 & & & \\
\hline
\end{tabular}

The chart shown in Figure 3 is based on the readings obtained immediately after the race. It shows the normal curve, the curve based on the arerage of all the cases after the race, and the blood-pressure readings in 
the murmur cases. It will be noted that the total average curve is now below the normal line, whereas before the race it was about $25 \mathrm{~mm}$. above the line. It will also be noted that the murmur cases suffered a greater fall than the others.

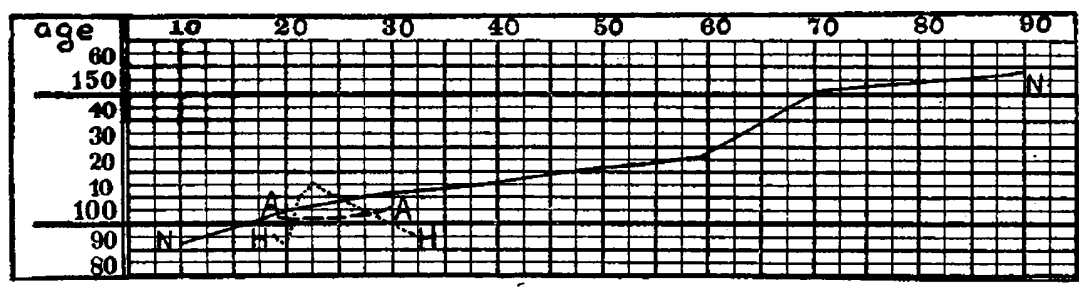

Fig. 3.-Average maximum blood-pressure after the race in the contestants with heart murmurs (line $\mathrm{H}-\mathrm{H}$ ) and in all contestants (line $\mathbf{A} \cdot \mathbf{A}$ ) compared with normal curve (line $\mathrm{N}-\mathrm{N}$ ).

\section{HEART CASES IN TIUE RACE}

Of the 5 runners who had murmurs before the race, $t$ ran the full distance and one ran nineteen miles. Three of these were among the first 12 to finish the race. These runners were all new to long-distance running.

After the race the hearts were auscultated in the first 45 as they finished. Out of the 29 that finished within the time limit (four hours, fifteen minutes) 5 presented heart conditions. Table 16 shows the place in which they finished. The fourth column in Table 16 shows the proportion of the pulse-pressure after the race to that before.

TABLE 16.-PCLSE-PRESSURE BEFORE AND AFTER THE RACE IN RUNNERS WITH HFART SYMPTOMS

\begin{tabular}{|c|c|}
\hline $\begin{array}{l}\text { Finished. } \\
\text { 2nd } \ldots \ldots\end{array}$ & $\begin{array}{l}\text { Before Race. } \\
\text { Muffled apex first }\end{array}$ \\
\hline $3 \mathrm{rd} \ldots$ & 0 \\
\hline 4th... & Systolic apex \\
\hline 5th... & O \\
\hline ith... & Systolie apex \\
\hline 12 th. & Systolic pulmonic \\
\hline 29 th . . . . & o \\
\hline 39 th... & Systolic apex \\
\hline 4 ith... & Systolic apex \\
\hline 50th... & Arrbythmia \\
\hline
\end{tabular}

After Race.

Intermittent and weak

Systolic base

Systolic apex

systolic apex

o

0

Irregular

0

Not examined

Not examined

Pulse-Pressure. After. Before. 
These "heart subjects" had more rapid pulses and smaller pulsepressures as a result of the exertion. Their blood-pressures are shown in the charts, Figures 2 and 3.

\section{BLOOD-PRESSERE TEN DAYS SUBSEQUENT TO THE RACE}

At this time we find the blood-pressure about the same as before the race, or, rather, it was nearer the normal line than before.

TABLE 17.-AVERAGE MAXIMUM BLOOD-PRESSURE BEFORE, IMMEDIATELY AFTER, AND TEN DAYS SUBSEQUENT TO THE RACE

$\begin{array}{llll} & & & \\ \text { Before } \ldots \ldots \ldots \ldots \ldots \ldots \ldots \ldots \ldots & \mathbf{1 2 6 . 5} & \mathbf{5 3} \\ \text { Immediately after } \ldots \ldots \ldots \ldots \ldots \ldots \ldots & 107.3 & 38 \\ \text { Ten days subsequent. } \ldots \ldots \ldots \ldots \ldots & 124.7 & 19\end{array}$

Table 18 shows the average pulse-rate, maximum and minimum, and pulse-pressures in the horizontal and erect postures, as compared with the tables of the same data before and after.

TABLE 18.-AVERAGE MAXIMUM, MINIMUM AND PULSE-PRESSURES TEN DAYS SUBSEQUENT TO RACE

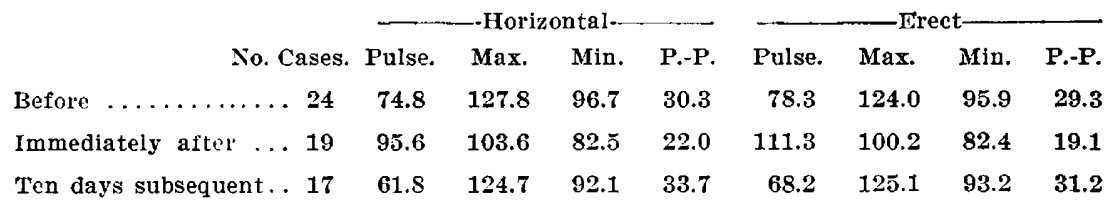

The readings in the individual cases are to be seen in Table 19, and these cases, arranged according to age of subjects, are given in Table 20 .

TABLE 19.-INDIVIDUAL MAXIMUM, MINIMUM AND PULSE-PRESSURES TEN DAYS SUBSEQUENT TO RACE

\begin{tabular}{|c|c|c|c|c|c|c|c|c|c|c|c|c|c|}
\hline & & & & & & SUBS & QUEX & & & & & & \\
\hline & & --Hor & & $\mathrm{B}, \mathrm{P}$ & - & $\ldots$ & - Ere & - & - & & & lt & \\
\hline No. & Age. & Pulse. & S. & D. & P.P. & Pulse. & s. & D. & P.P. & P. & S. & D. & P.-P. \\
\hline 4 & 18 & 50 & 125 & 88 & 37 & 52 & 130 & 95 & 35 & + & + & + & - \\
\hline 5 & 28 & 76 & 119 & 90 & 29 & 80 & 120 & 90 & 30 & + & + & $=$ & + \\
\hline 7 & 36 & 64 & 124 & 87 & 37 & 70 & 118 & 100 & 18 & + & - & + & - \\
\hline 11 & 19 & 62 & 120 & 85 & 35 & 80 & 130 & 100 & 30 & + & + & + & - \\
\hline 12 & 21 & 68 & 152 & 100 & 52 & 74 & 152 & 100 & 52 & + & $=$ & $=$ & $=$ \\
\hline 13 & 22 & 63 & 110 & 75 & $3 \breve{3}$ & 66 & 110 & 80 & 30 & + & $=$ & + & - \\
\hline
\end{tabular}


TABLe 19.-CONTINUED

SUBSEQUENT

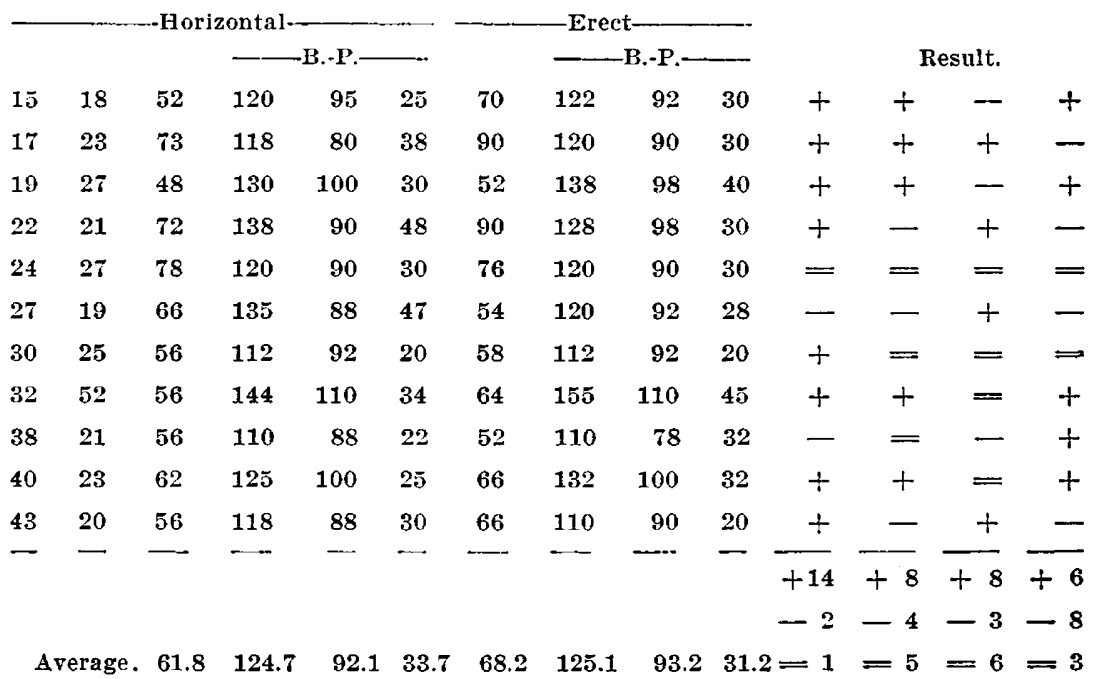

TABLE 20.-PRESSURE READINGS TEN DAYS SUBSEQUENT TO RACE, ARRANGED ACCORDING TO AGE OF SUBJECTS

HORIZONTAL,

-Age 18 to 20 - -Age 20 to 25 - -Age 25 to 30 - Age 35 to 40 Max. Min. P.-P. Max. Min. P.-P. Max. Min. P.-P. Max. Min. P.-P.

$\begin{array}{llllllllllll}125 & 88 & 37 & 152 & 100 & 52 & 119 & 90 & 29 & 124 & 87 & 37\end{array}$

$\begin{array}{llllllllllll}120 & 85 & 35 & 110 & 75 & 35 & 130 & 100 & 30 & \ldots & \ldots & \ldots\end{array}$

$\begin{array}{llllllllllll}100 & 95 & 25 & 118 & 80 & 38 & 120 & 90 & 30 & \ldots & \ldots & \ldots\end{array}$

$\begin{array}{llllllllllll}135 & 88 & 47 & 138 & 90 & 48 & 112 & 92 & 20 & \ldots & \ldots & \ldots\end{array}$

$\begin{array}{lllllllllllll}\ldots & \ldots & \ldots & 110 & 88 & 22 & \ldots & \ldots & \ldots & \ldots & \ldots & \ldots\end{array}$

$\begin{array}{llllllllll}\ldots & \ldots & \ldots & 125 & 100 & \mathbf{2 5} & \ldots & \ldots & \ldots & \text { AGE } 52\end{array}$

$\begin{array}{llllllllllll}\ldots & \ldots & \ldots & 118 & 88 & 30 & \ldots & \ldots & \ldots & 144 & 110 & 34\end{array}$

Average :

$\begin{array}{lllllllll}120 . & 89 . & 36 . & 124.3 & 90 . & 35 . & 120 . & 70 . & 27 .\end{array}$

\begin{tabular}{|c|c|c|c|c|c|c|c|c|c|c|c|}
\hline \multicolumn{12}{|c|}{ ERECT } \\
\hline 130 & 95 & 35 & 152 & 100 & 52 & 120 & 90 & 30 & 118 & 100 & 18 \\
\hline 130 & 100 & 30 & 110 & 80 & 30 & 138 & 98 & 40 & $\ldots$ & $\ldots$ & $\ldots$ \\
\hline 122 & 92 & 30 & 120 & 90 & 128 & 120 & 90 & 30 & $\ldots$ & $\ldots$ & . \\
\hline 120 & 92 & 28 & 128 & 98 & 30 & 112 & 92 & 20 & $\ldots$ & $\ldots$ & . \\
\hline$\ldots$ & $\ldots$ & . & 110 & 78 & 32 & $\ldots$ & $\ldots$ & $\ldots$ & $\ldots$ & $\ldots$ & $\ldots$ \\
\hline$\ldots$ & $\ldots$ & . & 132 & 100 & 32 & $\ldots$ & $\ldots$ & $\ldots$ & & GE 52 & \\
\hline$\ldots$ & $\ldots$ & $\ldots$ & 110 & 90 & 20 & $\ldots$ & $\ldots$ & $\ldots$ & 155 & 110 & 45 \\
\hline
\end{tabular}

Average :

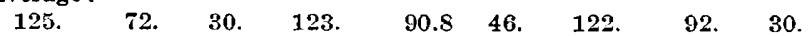


Six months later we examined five of these runners and found the blood-pressures lower than at the previous examination; their pressures were gradually lowering toward the normal average. The readings in these cases are seen in Table 21 .

TABLE 21.-PRESSLIE READINGS IN FIVE CASES SIX MONTHS AFTER RACF

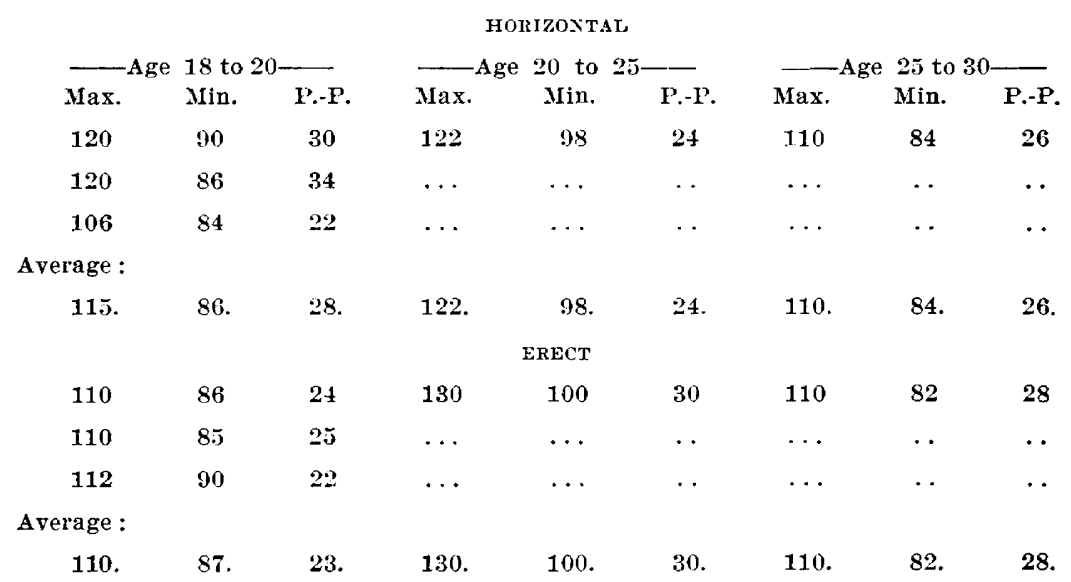

The chart shown in Figure 4 is based on the findings at the examinations ten days and six months after the race. The curve at the final examination is nearer the normal level.

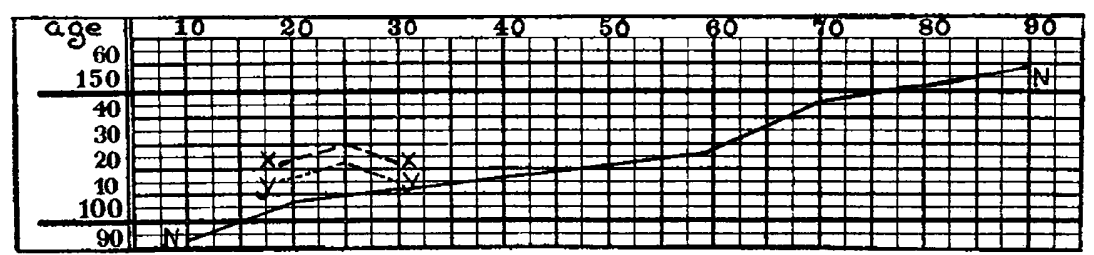

Fig. 4.-Average maximum blood-pressures (all contestants) obtained ten days (line $\mathrm{X} \cdot \mathrm{X}$ ) and six montlıs (line $\mathrm{Y}-\mathrm{Y}$ ) after the race, compared with normal curve (line $\mathrm{N}-\mathrm{N}$ ).

Each of the four charts $5,6, \gamma$ and 8 represents the blood-pressure curve of an individual case. They all show the marked fall resulting from the excrtion, the height of the blood-pressure ten days after the race and the extent to which it had fallen at the end of six months. In the case of $\mathrm{II}-\mathrm{e}$ it will be noted that at the end of six months his blood-pressure did not recede toward the normal level as the others; the reason for this is that he had kept up his training and long-distance running to the very day of the last examination. With the high pressure he 
still had the mitral systolic loud blowing murmur which he presented at all of the previous examinations.

In the last case, that of $\mathrm{O}-\mathrm{n}$, who had a murmur before and immediately after the race, it was found ten days later that the murmur could be brought out only by his pacing, and at the end of six months, even after pacing for a full half minute, it could not be heard. In this case, with the disappearance of the hypertrophy which was accompanied by a falling of the blood-pressure, there was a simultaneous disappearance of the murmur.

COMPARISON OF BLOOD-PRESSURE OBSERVATIONS BEFORE, IMMEDTATELY

AFTER AND TEN DAYS AND SIX MONTHS SUBSEQUENT TO THE RACE

On the tables 1 to 21 I have constructed Charts 1 to 9 . All considered, the conclusions from these evidences are that as a result of training for the Marathon race a state of increased blood-pressure is developed, which is considerably above normal. In some cases when training is

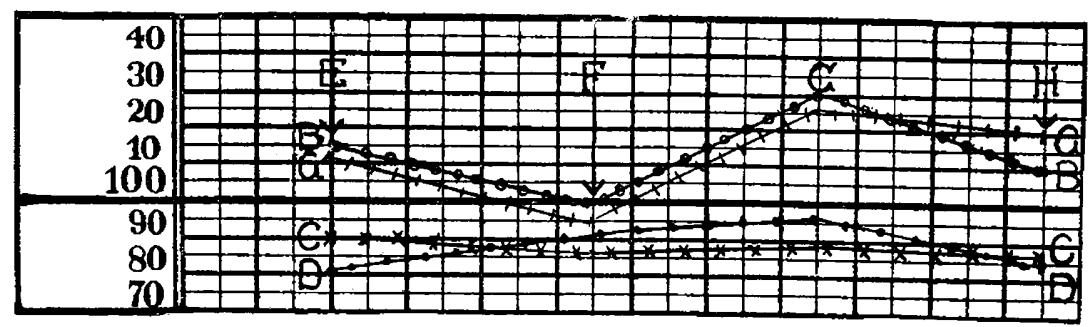

Fig. 5.-Blood-pressures, case of $\mathrm{H} \cdot \mathrm{n}$; line A-A, maximum horizontal; line $\mathrm{B}-\mathrm{B}$, maximum erect; line $\mathrm{C}-\mathrm{C}$, minimum horizontal; line $\mathrm{D}-\mathrm{D}$ minimum erect; $\mathrm{E}$, before race; $F$, immediately after; $G$, ten days, and $H$, six months subsequent to race.

carried to a more severe degree or because of a preceding state of the heart, we find still higher blood-pressures associated with heart murmurs.

As a result of the race the maximum, minimum and pulse-pressures in all cases are lowered, reaching a point below the normal average; and in the "heart" cases a greater fall is suffered than in the others.

Ten days subsequent to the race we find the blood-pressure about the same as before the race, or, rather, it is nearer the normal line. Six months after the race we find the blood-pressure lower than it was at the previous examination; i. e., still nearer to the normal.

EFFECT OF CHANGE OF POSTURE ON BLOOD-PRESSURE

The observations were made first in the horizontal and then in the erect posture. The surrounding conditions were as follows: Being in 
June, the extcrnal temperature was warm. The contestants were stripped; they had been weighed, measured, hearts auscultated, all of which allowed them about ten minutes in the room previous to the blood-pressure examination. They then walked over to the table and lay down, after which the armlet was applied. Within three to five minutes the reading was

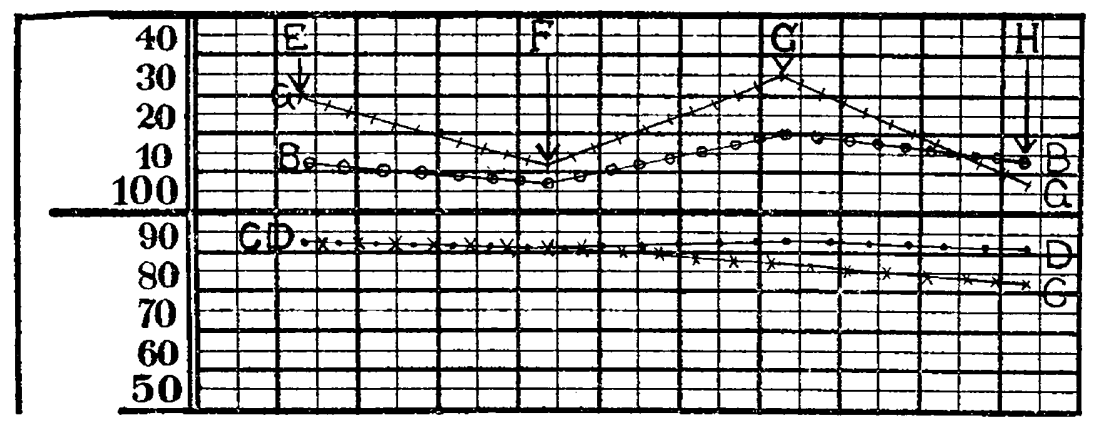

Fig. 6.-Blood-pressures, case of $\mathrm{M}$-e; maximum and minimum, horizontal and erect, and times of examination indicated as before. Mitral systolic murmur heard at each examination.

made. Without removing the cuff they were directed to get up and stand beside the table, not being allowed to lean against it, while the second reading was made. After the race they were laid on the table imme-

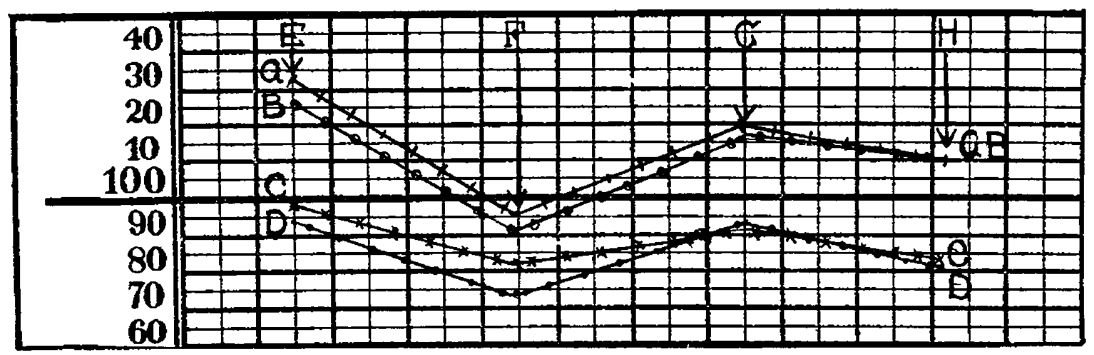

Fig. 7.-Blood-pressures, case of $\mathrm{H}$-s ; maximum and minimum, horizontal and erect, and times of examination, indicated as before.

diately on entering the medical tent (on a run). While I was making the blood-pressure observation another man counted the pulse. When this was done, the contestant was directed to get up, in many instances having to be assisted; to stand as erect as possible without leaning against the table while the second reading was being made. The technic of the subsequent examinations was the same as that of the first. This change from 
the horizontal to the erect posture caused alterations in the blood-pressure which may be seen in the last columns of Tables 5, 14 and 19 . These effects are summarized in Table 22.

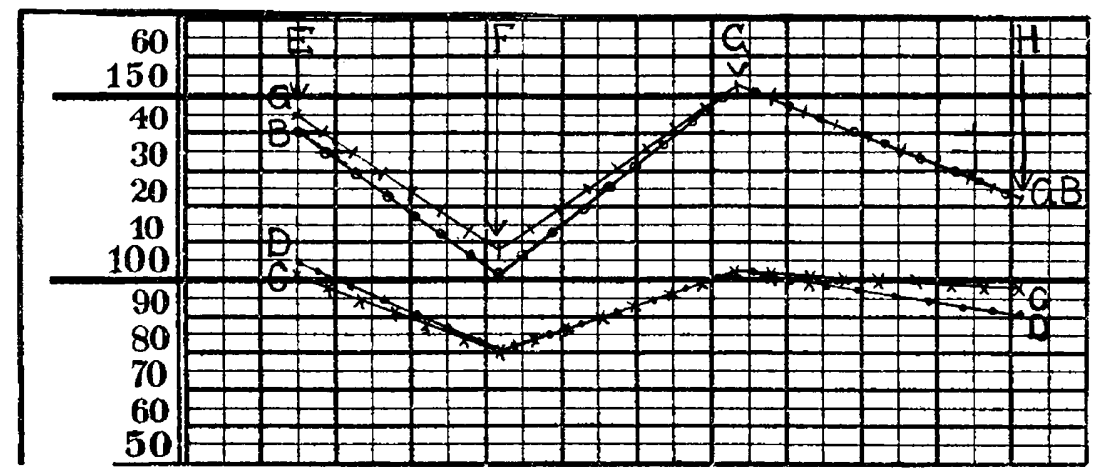

Fig. 8.-Blood pressures, case of $\mathrm{O}-\mathrm{n}$; maximum and minimum, horizontal and erect, indicated as before. Pulmonary systolic murmur heard before, after, and at the third examination, but at the time of the fourth examination it had disappeared.

TABLE 22.- EFFECT OF CHANGE OF lOSTURE ON BLOOD-PRESSURE

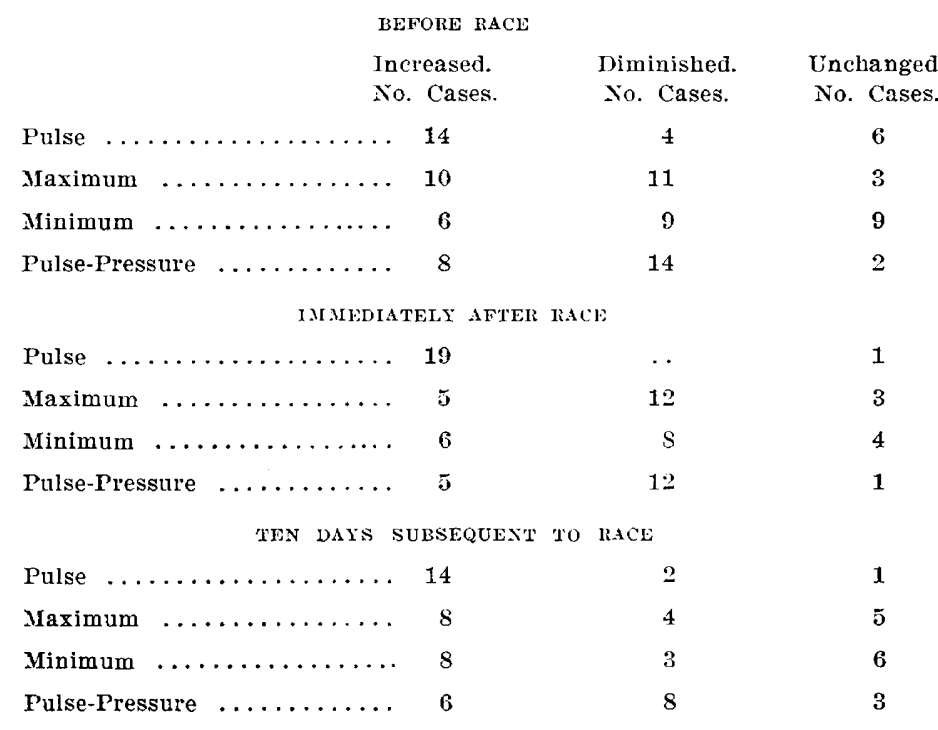

CONCLUSIONS IN REGARD TO EFFECT FROM CHANGES OF POSTURE

Before Race.-From these observations we may then say that in individuals with sound hearts having a definite degree of hypertrophy, as a 
result of change in posture, from the horizontal to the erect, there is a rise in pulse-rate, the maximum pressure may be increased or diminished, the minimum pressure may be diminished or equal, and with this there will be a diminution of pulse-pressure. This occurs in more than half of the cases.

A
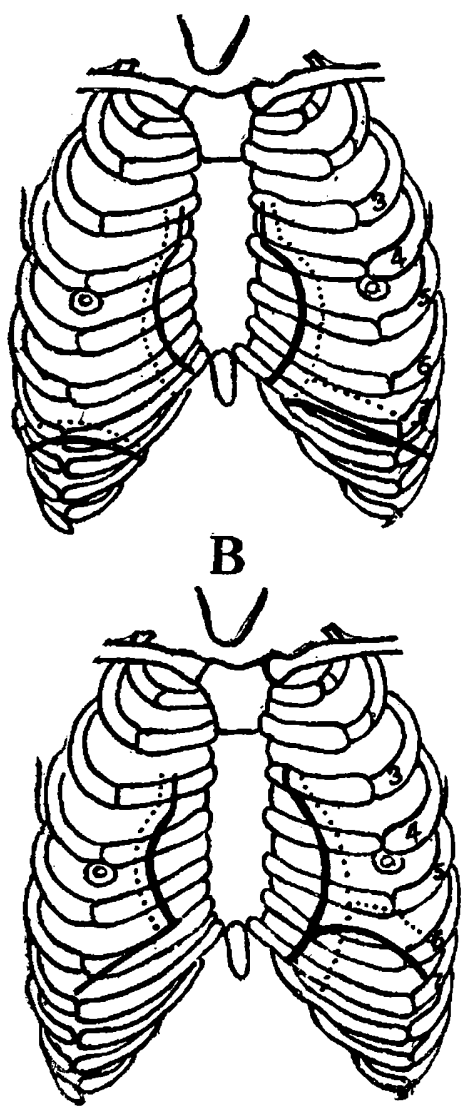

C
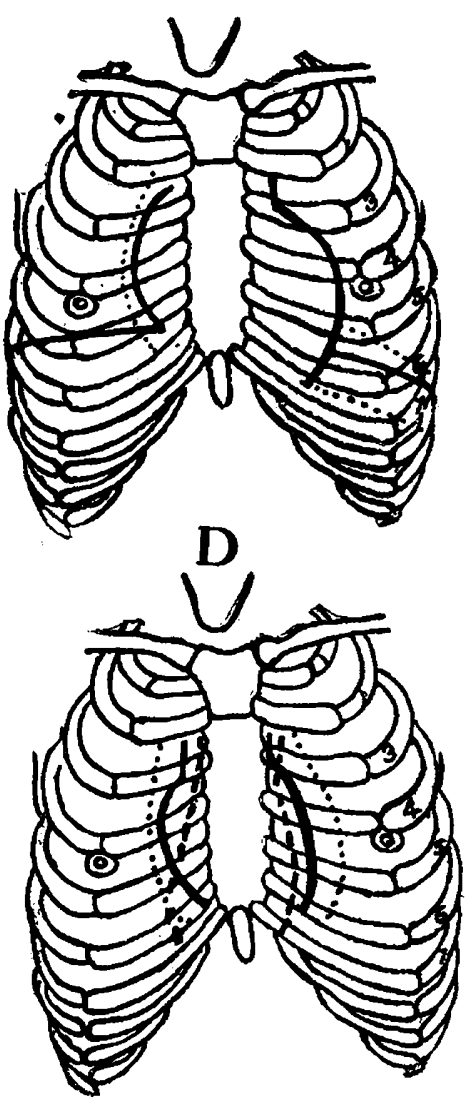

Fig. 9.-Fluoroscopic studies made by Drs. John W. Boyce and George W. Grier. Solid line indicates examination before, dotted line, immediately after, and line composed of dashes, examination a week after the race. A, small heart; contestant dropped out at one mile; B, heart right size; contestant finished No. 11: C, large heart, left dilatation; D, average case.

Inmediately After Race.-Following severe muscular exertion, in the greater number of cases, the change from the horizontal to the erect posture causes an increase in pulse-rate, a falling of maximum and minimum pressure, and with this a lowering of pulse-pressure. 
Ten Days and Six Months Subsequent to the Race.-The changes were the same as before the race.

Effect of Change of Posture in Heart Cases.-So far as could be seen these cases did not show a more striking uniformity in reaction to the change of posture than the other cases.

Relations of Maximum, Minimum and Pulse-Pressures to Each Other. -In most of these records it will be seen that the height of the minimum pressure was in proportion to the maximum, and that the pulse-pressure was greatest in those cases showing the highest maximum pressures.

\section{RELATION OF X-RAY FINDINGS TO BLOOD-PRFSSURE}

This work was carried out by Dr. John W. Boyce and Dr. George Grier with their assistants at the West Penn Hospital. They classified the cases examined before the race as (a) small hearts, (b) hearts of the "right size" and (c) large hearts. Those of the first group were not small as compared to normal hearts; they were, in fact, larger than normal, but they were the small hearts of this series. The average maximum blood-pressure of the small heart cases was $124 \mathrm{~mm}$., while the average of the hearts of the "right size" and large heart series was $138 \mathrm{~mm}$. Of six cases that had "small hearts," none finished the race. Of 17 that had hearts of the "right size," seven finished. This means that with the compensatory hypertrophy there comes increased endurance. After the race, within three-quarters of an hour in most instances, tracings of heart shadows were again made. The degree of dilatation varied.

The average fall in the cases of maximum pressure as a result of the race in those cases presenting a large degree of dilatation, was $31 \mathrm{~mm}$., while the average fall of maximum pressures in those outlined as showing little change in the heart shadow was $12 \mathrm{~mm}$.

RENAL SYSTEM

Before Race.-The urine was examined in 24 cases. One showed less than 0.1 per cent. of albumin, which was not of renal origin. There were no casts in any. On standing over night, crystals of calcium oxalate were deposited in five specimens.

Immediately After Race.-Amount: We succeeded in getting 19 specimens, and in those the total quantity excreted during the time of the race, which lasted between three hours and fourteen minutes to five hours. The largest amount was 220 c.c. and the smallest was 35 c.c.

Color: This varied from normal to dark smoky amber; in several it was bloody. 
Reaction: This was alkaline in those containing considerable blood, and in the others it was acid.

Specific Gravity: This varied from 1012 to 1035 . There was no ratio between the amount and the specific gravity.

Total Solids: These varied from $2.2 \mathrm{gm}$. to $13.51 \mathrm{gm}$. The presence of blood makes the estimation valueless. Even on eliminating the cases in which there was considerable blood in the urine, I could find no ratio between the solids and the loss of body weight during the race, nor to the total amount of urine.

Albumin: Every specimen showed albumin from mere trace to a heavy cloud.

Sugar: A positive reaction was not obtained in any case.

Acetone Bodies: Diacetic Acid: With ferric chlorid a typical reaction was obtained in 3 cases; it was distinctly present in 10, and in large amounts in 4 cases. It was absent in the case in which there was the largest amount of urine passed and present in small amount in the next largest specimen. Acetone: The acetone reaction was less marked, but present. Beta-oxybutyric acid was tested and found in one of the specimens. The nature of the diacetic and acetone reactions was verified by H. L. Amos of the West Penn Hospital, to whom I am indebted for the examination of a number of specimens.

Microscopic Examination: Every one of the 19 cases showed casts; five of them showed "showers of casts." All but the largest specimen showed red blood cells; three showed large amounts of blood. In one specimen I found fat globules.

At Subsequent Periods.-Out of the 19 specimens examined at the end of a week, 4 showed light clouds of albumin and as many had casts. Two showed casts without albumin.

Three weeks after the race, 3 that did not show albumin before the race still showed traces of albumin and casts.

\begin{tabular}{|c|c|c|c|c|c|c|}
\hline \multirow[t]{2}{*}{ TABLE } & \multicolumn{4}{|c|}{$\begin{array}{l}\text { FINDINGS BEFORE THE RACE, } \\
\text { AND AT SUBSEQUENT PERIODS }\end{array}$} & \multicolumn{2}{|c|}{ IMMEDIATELY AFTER } \\
\hline & No. of & Cases. & Albumin. & Blood. & Casts. & Acet. Bodies. \\
\hline Before & & 24 & 1 & 0 & 0 & 0 \\
\hline Immediately after ... & $\ldots$ & 19 & 19 & 18 & 19 & 18 \\
\hline One week subsequent & & 19 & 4 & 0 & 6 & 0 \\
\hline Three weeks subsequent & & $\ldots$ & 3 & 0 & 3 & 0 \\
\hline
\end{tabular}


RELATION OF CIRCULATORY TO RENAL SYSTEM (AS ESTIMATED BY URINARY FINDINGS)

Table 24 gives the age, maximum and pulse-pressures before and after the race in the horizontal position; the amount of urine and approximate amounts of albumin and acetone bodies.

TABLE 24.-RELATION BETWEeN CIRCULATORY AND RENAL SysteM (URINARY FINDINGS)

\begin{tabular}{rrrrrrrr} 
& Hor. B.-P. Before & \multicolumn{2}{c}{ Urine- } & Hor. B.-P. After & \\
\cline { 3 - 7 } Age. & Max. & P.-P. & C.C. & Albumin. & Max. & P.-P. & Acet. Bodies. \\
18 & 140 & $\ldots$ & 220 & I & 100 & $\ldots$ & $\ldots$ \\
36 & 140 & $\ldots$ & 205 & I & 110 & $\ldots$ & $\ldots$ \\
25 & 145 & $\ldots$ & 200 & $1 / 2$ & 130 & $\ldots$ & $\ldots$ \\
27 & 122 & 32 & 195 & I & 110 & 25 & I \\
19 & 122 & $\ldots$ & 195 & I & 110 & $\ldots$ & $\ldots$ \\
18 & 122 & $\ldots$ & 190 & III & 96 & $\ldots$ & $\ldots$ \\
$?$ & 115 & $\ldots$ & 190 & II & 88 & $\ldots$ & $\ldots$ \\
$?$ & 120 & 32 & 175 & I & 120 & 32 & II \\
31 & 138 & $\ldots$ & 170 & II & 92 & $\ldots$ & $\ldots$ \\
36 & 132 & 32 & 170 & III & 88 & $?$ & III \\
$?$ & 132 & 38 & 170 & I & 122 & 34 & O \\
52 & 134 & 34 & 150 & I & 118 & 26 & I \\
19 & 118 & 26 & 130 & $1 / 2$ & 114 & 24 & IV \\
25 & 110 & 20 & 125 & I & 110 & 15 & I \\
20 & 115 & $\ldots$ & 120 & I & 98 & $\ldots$ & $\ldots$ \\
20 & 115 & $\ldots$ & 75 & III & 130 & $\ldots$ & $\ldots$ \\
21 & 135 & 45 & 35 & III & 108 & $\ldots$ & $\ldots$ \\
23 & 135 & 45 & $?$ & III & 100 & 20 & I
\end{tabular}

From this table it may be seen that the subjects having the highest maximum pressures before the race excreted the largest amounts of urine during the race. The pulse-pressures were obtained in only part of this series, and their relation to the amount of urine seems variable.

Albumin was present in small amounts in the cases in which the larger quantities after the race were passed.

Albumin was present in largest amounts in those cases which show the greatest fall in the maximum blood-pressures; and in those which showed the most marked falls in the pulse-pressures.

From these observations on the renal functions, it seems that the more serious the disturbance of the general circulatory system, the more marked are the evidences of this disturbance in the renal circulation, and 
this is evidenced by the amount of blood, degree of albuminuria and cylindruria.

As to diacetic acid, all considered, it seems that it was found in larger amounts in the urine from those who ran most successfully-i. e., those who ran hardest in the shortest time. Undoubtedly, many other factors play a part in this. The amount of acetone seemed small in proportion to the diacetic acid; one way to account for this is perhaps that it was largely eliminated by the respiratory effort

\section{CONCLUSIONS}

In the conclusion of this study, it may be said that the most marked changes which occur in the contestants who train for and compete in this race are as follows:

Before the Race.-The average individual who has trained for this race will, about the time he is in good training condition, have a pulse that is moderately slower than normal, with a normal diurnal variation. His blood-pressure is higher than that of the average individual, and with this he has developed a compensatory hypertrophy. If in his case it is found that he has a greater than normal diurnal pulse variation, that will be associated with a higher than average blood-pressure.

Or we may say that from these observations we are led to believe that the individual who has this more than average compensatory hypertrophy and higher blood-pressure, will have a greater number of heart-beats in the twenty-four hours. The average heart shadow as seen with the $x$-ray is larger than normal in nearly all cases, and some will show comparatively very large hearts. The subjects showing the larger hearts are the ones that have the higher blood-pressures.

In the contestant who as a result of hard training, or because of some unknown preceding state of his heart, has developed a heart murmur, there will be found the very large heart and higher blood-pressure. Body overweight, laborious occupation, short and severe training are productive of higher than average blood-pressures and associated hypertrophy.

After the Race.-As a result of this inordinate exertion, if he is of the average class, he will have a fall of about 20 per cent. in his bloodpressure; if he is of the "heart-murmur cases," he will have a still greater fall in his blood-pressure. If his heart shadow with the $x$-ray shows a marked increase in size (much dilatation), his blood-pressure will have a greater fall than if his heart shadow remains about the same size (slight dilatation).

At the end of six months the blood-pressure is still nearer the normal level than at the previous examination. 
Most of these contestants had been running during the preceding six or nine months, and it is natural to expect a gradual disappearance of the established hypertrophy, as our findings bear out.

The change of posture from the horizontal to the erect is followed by certain accommodative changes in the blood-pressures, these depending largely on the reserve energy of the circulatory system, and the promptness with which it reacts to the force of gravity.

The effect of this severe bodily exertion on the kidneys is definitely proportionate to the degree of general circulatory disturbance, of which the renal circulation is part.

In these studies we have had the rare opportunity of observing the transition stage from health to disease. Beginning as physiologic changes many of these cases have transgressed the dividing zone entering into that of the pathological. The exciting factors once removed, a recession into the normal followed, in some cases reaching the physiological quickly, others slowly, while some, it may be, will never return to normal.

In closing, I wish to say that for the opportunity of studying these cases, and for innumerable suggestions that made this work possible, I am deeply indebted to Dr. Watson L. Savage, Physical Director of the Pittsburg Athletic Association, and Carnegie Technical Schools; and then to express my sincerest thanks to the men whose names are here appended, for their careful, valuable and enthusiastic assistance. Without their aid such an undertaking as this would have been impossible.

4502 Fifth Avenue.

DR. E. S. DICKEY,

Dr. O. B. McABoY,

Dr. C. Orbin,

Dr. C. L. Palmer,

Dr. Frank D. Stolzenbach,

DR. H. G. Wertheimer,

DR. A. W. Woodburx. 